\title{
Water and sewage systems, socio-demographics, and duration of residence associated with endemic intestinal infectious diseases: A cohort study
}

\author{
Kay Teschke ${ }^{1 *}$, Neil Bellack', Hui Shen ${ }^{1}$, Jim Atwater ${ }^{2}$, Rong Chu', Mieke Koehoorn', Ying C MacNab',
} Hans Schreier ${ }^{3}$, Judith L Isaac-Renton ${ }^{4}$

\begin{abstract}
Background: Studies of water-related gastrointestinal infections are usually directed at outbreaks. Few have examined endemic illness or compared rates across different water supply and sewage disposal systems. We conducted a cohort study of physician visits and hospitalizations for endemic intestinal infectious diseases in a mixed rural and urban community near Vancouver, Canada, with varied and well-characterized water and sewage systems.
\end{abstract}

Methods: Cohort members and their disease events were defined via universal health insurance data from 1995 through 2003. Environmental data were derived from municipal, provincial, and federal government sources. Logistic regression was used to examine associations between disease events and water and sewage systems, socio-demographic characteristics, and temporal factors.

Results: The cohort included 126,499 individuals and approximately 190,000,000 person-days. Crude incidence rates were 1,353 physician visits and 33.8 hospitalizations for intestinal infectious diseases per 100,000 person-years. Water supply chlorination was associated with reduced physician visit incidence (OR: 0.92, 95\% Cl 0.85-1.0). Two water systems with the highest proportions of surface water had increased incidence (ORs: 1.57, 95\% Cl 1.39-1.78; and $1.45,95 \% \mathrm{Cl} 1.28-1.64)$. Private well water and well depth were not associated with increased risk, likely because of residents' awareness of and attention to water quality. There was increased crude incidence with increasing precipitation in the population served by surface water supplies, but this trend did not remain with adjustment for other variables. Municipal sewer systems were associated with increased risk (OR: 1.26, 95\% Cl 1.141.38). Most socio-demographic variables had predicted associations with risk: higher rates in females, in the very young and the elderly, and in residents of low income areas. Increased duration of area residence was associated with reduced risk (OR, duration $\geq 6$ years: $0.69,95 \%$ Cl 0.60-0.80 vs. $<1$ year: 1.16, 95\% Cl 1.03-1.30).

Conclusions: This large cohort study, with objective data on exposures and outcomes, demonstrated associations between endemic infectious intestinal diseases and factors related to water supply, sewage disposal, sociodemographics, and duration of residency. The results did not always follow prior expectations based on studies examining outbreaks and single systems, and underscore the importance of studying factors associated with endemic disease across water and sewage system types.

\footnotetext{
* Correspondence: kay.teschke@ubc.ca

${ }^{1}$ School of Population and Public Health, University of British Columbia,

Vancouver, Canada

Full list of author information is available at the end of the article
} 


\section{Background}

Most studies of water and enteric infections have focused on disease outbreaks in single water systems [1]. High profile examples in North America include the 1993 Milwaukee Cryptosporidium outbreak where approximately 100 people died and a further 400,000 became ill [2], and the 2000 Walkerton Escherichia coli O157 and Campylobacter outbreak that caused 7 known deaths and about 2,300 illnesses [3-5].

Few studies have examined non-epidemic illness. Canadian surveillance data suggest that potentially waterborne intestinal infectious diseases account for about $20 \%$ of reported communicable disease cases [6,7]. A number of investigations have examined factors influencing endemic intestinal disease within water systems, including turbidity, chlorination, residence time, and system maintenance [8-14]. Studies of endemic disease across multiple water or sewage systems are very rare [15-17].

We investigated the association between the incidence of intestinal infectious diseases and environmental factors potentially contributing to drinking water quality in the Township of Langley in the Metro Vancouver area of British Columbia (BC), Canada. The Township was selected for study, not because of concerns about endemic disease in the area, but because it encompasses rural and urban areas with varied and well-characterized water supply and sewage disposal systems. In addition, individual-level data were available about physician visits and hospitalizations, and about socio-demographic characteristics of the population that might also be associated with disease events.

\section{Methods}

The study methods were reviewed and approved by the University of British Columbia Behavioural Research Ethics Board and by the British Columbia Ministry of Health Services data steward.

\section{Cohort identification}

The cohort was identified by Population Data BC [18]. Its data holdings include the Client Registry of the provincial Medical Services Plan (universal health insurance, estimated to enumerate over $95 \%$ of the population), all hospital discharge records, and billing records for visits to physicians. The cohort included all individuals who lived in the Township for at least 6 months between January 1, 1995 and December 31, 2003.

\section{Disease events}

Two types of disease events were identified by linking cohort members to administrative records: a) Physician visit, a record in the Medical Services Plan Billings File with a 3-digit International Classification of Diseases, $9^{\text {th }}$ Revision (ICD-9) [19] "diagnostic code" listed in Table 1; and b) Hospitalization, a record in the Hospital
Discharge Records File with a "most responsible diagnosis" or "primary diagnosis" indicating a 3- to 5-digit ICD-9 code in the range listed in Table 1.

The ICD-9 codes were selected in consultations between the study medical microbiologist (JLI-R) and Dr. Robert Fisk of the BC Ministry of Health Services [personal communication, September 2003] to include intestinal infectious diseases with potential to be waterborne and, where possible within the constraints of disease coding, to exclude diseases known not to be associated with waterborne disease transmission in Canada, such as cholera, typhoid fever, and amoebiasis, and gastrointestinal illnesses known to be predominantly food-borne (e.g., staphylococcal food poisoning, botulism, enteritis necroticans).

\section{Socio-demographic and temporal variables}

Data on sex and birth date were abstracted from the Client Registry. Season was defined as spring (March 1 to May 31), summer (June 1 to August 31), fall (September 1 to November 30 ) and winter (December 1 to February 29 ) to correspond more closely to local weather, employment, and school attendance patterns than classical seasonal definitions, and thus to control for seasonal patterns of interpersonal contact that might influence person-to-person transmission (e.g., indoor living, school year). Duration of residence in the Township was categorized as $<1$ year, $1-<2$ years, $2-<3$ years, $3-<6$ years, $\geq 6$ years, and unknown. Household income quintile of the neighborhood was derived from Statistics Canada 2001 census data available for each dissemination area (one or more neighboring blocks with a population of

\begin{tabular}{|c|c|c|c|}
\hline \multirow[b]{2}{*}{$\begin{array}{l}\text { ICD-9 } \\
\text { Code* }\end{array}$} & \multirow[b]{2}{*}{$\begin{array}{l}\text { Disease } \\
\text { description }\end{array}$} & \multicolumn{2}{|c|}{ Number of subjects with a } \\
\hline & & physician visit & hospitalization \\
\hline 003 & $\begin{array}{l}\text { Other Salmonella } \\
\text { infections }\end{array}$ & 65 & 0 \\
\hline 004 & Shigellosis & 20 & 0 \\
\hline 007 & $\begin{array}{l}\text { Other protozoal intestinal } \\
\text { diseases (includes } \\
\text { balantidiasis, } \\
\text { giardiasis, coccidiosis, } \\
\text { intestinal trichomoniasis, } \\
\text { cryptosporidiosis, } \\
\text { cyclosporiasis) }\end{array}$ & 21 & 0 \\
\hline 008 & $\begin{array}{l}\text { Intestinal infections due } \\
\text { to other organisms }\end{array}$ & 721 & ${ }^{\dagger} 180$ \\
\hline \multirow[t]{2}{*}{009} & $\begin{array}{l}\text { III-defined intestinal } \\
\text { infections }\end{array}$ & 6190 & 0 \\
\hline & Total all diseases above & 7017 & 180 \\
\hline
\end{tabular}

* International Classification of Diseases, $9^{\text {th }}$ Revision [19] 
400 - 600 persons), and assigned via residential postal code. Population density was calculated as the average number of persons per hectare per year at each property. Distance to nearest hospital was calculated from the center of each property to the nearest of two local hospitals, and classified as $<1 \mathrm{~km}, 1-<3 \mathrm{~km}$, and $3-<8 \mathrm{~km}$.

\section{Environmental variables potentially contributing to drinking water quality}

Environmental variables were linked geographically via spatial link functions in ArcGIS 9 (ESRI, Redlands, CA) using latitude and longitude coordinates, unique property identifiers, or street addresses, then linked to subjects via street addresses at the Ministry of Health Services.

\section{Water system}

All addresses supplied by municipal water systems were identified via Township tax records of water connection, further specified as one of 7 categories by location. This allowed distinctions between municipal systems served by wells only (further categorized by the numbers of homes served as small, with $<100$ connections, or large systems), and those with mixed water systems supplied from both Township wells and protected surface water reservoirs in the North Shore Mountains (further categorized by relative proportions of surface water in the mix). The municipal wells and distribution systems are managed and tested by the Township, and the reservoirs are managed and tested by the Greater Vancouver Water District. Addresses with water supplied by community systems were identified via Fraser Health Authority records. These systems are managed privately by each community, but tested by health authority officials. All remaining addresses were designated as having private systems (served by on-property wells, with no public health monitoring).

\section{Drinking water disinfection}

Dates of implementation of chlorination systems were used to indicate presence or absence of chlorine disinfection. Data were provided by the Township for the municipal systems and by Fraser Health Authority for the community systems. All private water supplies were designated as having no disinfection.

\section{Sewage disposal}

All residential addresses connected to the municipal sewage system were identified via Township tax records of sanitary sewer connection. All other addresses were designated as having private on-property sewage disposal. Land use

Property land uses were classified as agricultural or residential, via $\mathrm{BC}$ Assessment records.

\section{Well depth}

Data were available for a subset of wells from a database based on voluntary reporting by well drillers to the $\mathrm{BC}$ Ministry of Environment.

\section{Precipitation}

Daily precipitation data were downloaded from the Environment Canada National Climate Data for a station in the Coquitlam watershed in the North Shore Mountains, and assigned to properties receiving surface water from the mountain reservoirs.

\section{Survey of Township households}

To gather descriptive data not available from administrative sources, from fall 2006 to summer 2007, we conducted a survey of a random sample $(\mathrm{N}=1000)$ of households with Township postal codes, selected from the CanPages electronic directory. A self-administered questionnaire was mailed, followed by one telephone and two mailed reminders. It included questions about type of water supply, type of sewage disposal, use of tap water for cooking and drinking, filtration of tap water, and for appropriate subsets, questions about well depth and testing of water quality. Agreement between the survey and administrative data on water system type (municipal, community, or private) and sewage system type (municipal or private) was examined by calculating unweighted kappa statistics.

\section{Data analysis}

All statistical analyses were done using SAS 9.1 (SAS Institute, Cary, NC). The unit of analysis was personday, as most variables were time-varying and cohort membership was dynamic, with individuals moving within and in and out of the Township during the study period.

Initial examinations of the data included identification of intestinal infectious disease events, plots of their occurrence over the study period to check for evidence of epidemics, and examination of multiple event records per subject to ascertain the time periods between records.

Two sets of analyses were conducted, one for physician visits, the other for hospitalizations. Only the first physician visit and first hospitalization for each subject were included in analyses, to exclude the possibility that a subsequent event might be related to the first. Persondays after the first event were excluded. Disease events and person-days within the first 2 months after entry to the cohort (i.e., January 11995 for most subjects or the date of moving to the Township if after that date) were also excluded, to allow an incubation period sufficient for any associations to be plausibly related to exposures in the Township.

Person-time and crude disease incidence rates with 95\% confidence intervals (CI) were calculated for each category of each independent variable. The statistical estimation and inference reported here are based on fitting the following unconditional logistic regression 
model, using the full dataset and the PROC LOGISTIC procedure.

$$
\log i t\left(P_{i t}\right)=\beta_{0}+\sum_{j=1}^{M} \beta_{j} X_{j i t}
$$

where

$$
\log i t\left(P_{i t}\right)=\log \frac{P_{i t}}{1-P_{i t}} \text {, and } P_{i t}=\text { the probability of }
$$

a physician visit (or hospitalization) for an intestinal infectious disease for subject $\mathrm{i}$ on day $\mathrm{t}$, and $X_{j i t}=$ value for subject $i$ on day $t$ for each of $M$ variables. (Primary models for a priori hypotheses included the variables sex, age, season, duration of residence, household income quintile, drinking water disinfection, water system, sewage disposal, and land use; post-hoc analyses added distance to nearest hospital and population density to the primary models).

Log odds ratios and their standard errors were estimated using maximum likelihood methods, and 95\% confidence limits were based on the asymptotic normality of parameter estimators. Calendar year was also included in all models, because including only first events meant that they were weighted somewhat more heavily to the initial years. This variable was categorized as 1995-6, 1997-8, 1999-2001, and 2002-3, grouping years with nearly identical crude event rates.

For certain environmental variables apropos only to subsets of the data, secondary analyses were conducted. These analyses were restricted to physician visits only, because there were so few hospitalizations, and included all variables in the primary analyses. In one model, the analysis was restricted to those living at properties whose well depth was known, and well depth was
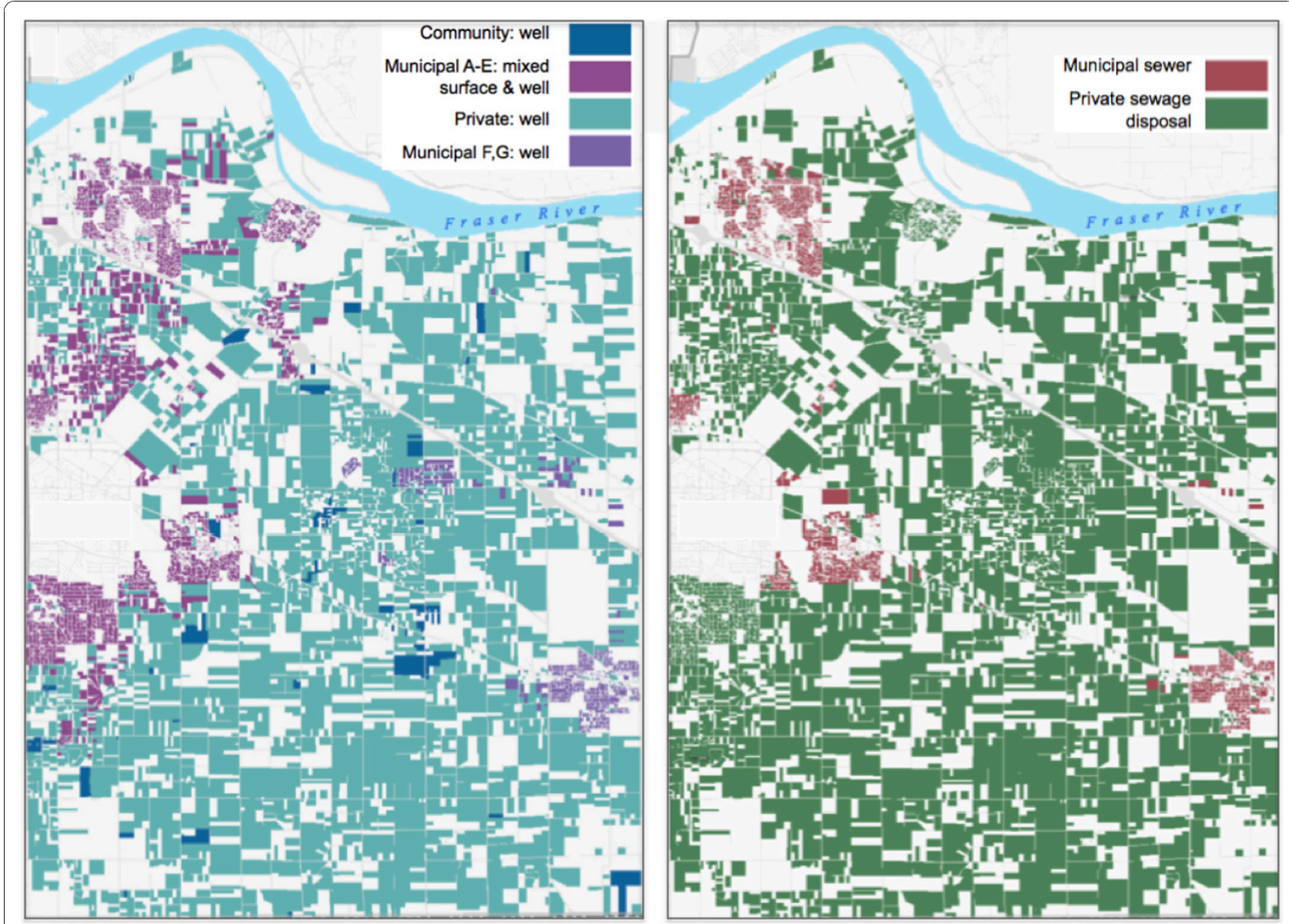

Figure 1 Maps showing geographic distributions of the water and sewage systems. Data for parcels in a mixed rural-urban community in the Metro Vancouver area of Canada, on July 1 1999, the mid-point of the study period (of a total of 29,458 parcels). Uncolored areas are parcels not included in the study, either because they were outside the Township or did not house a study subject on that date (e.g., industrial, commercial or park land, or vacant property). 
Table 2 Proportions of person-time and crude incidence rates of intestinal infectious diseases, 1995 to 2003 inclusive, stratified by categories of each socio-demographic, temporal, and environmental variable.

\begin{tabular}{|c|c|c|c|}
\hline Variable \& Category & $\begin{array}{l}\text { Proportion of person- } \\
\text { time in each category }\end{array}$ & $\begin{array}{r}\text { Crude rate of physician visits } \\
\text { per } 100,000 \text { person-years } \\
{[95 \% \mathrm{Cl}]}\end{array}$ & $\begin{array}{r}\text { Crude rate of hospitalizations }{ }^{\mathrm{b}} \\
\text { per 100,000 person-years } \\
{[95 \% \mathrm{Cl}]}\end{array}$ \\
\hline \multicolumn{4}{|l|}{ Sex } \\
\hline Female & $50.4 \%$ & $1,398[1351,1442]$ & $35.8[28.6,43.0]$ \\
\hline Male & $49.6 \%$ & $1,310[1265,1354]$ & $31.8[24.9,38.5]$ \\
\hline \multicolumn{4}{|l|}{ Age } \\
\hline$<1$ & $0.3 \%$ & $7,848[6484,9175]$ & $119[0,284]$ \\
\hline $1-4$ & $5.0 \%$ & 6,607 [6286, 6928] & $315[249,381]$ \\
\hline $5-9$ & $7.4 \%$ & $2,164[2014,2314]$ & $55.8[33.0,78.5]$ \\
\hline $10-19$ & $16.2 \%$ & $902[838,967]$ & $21.9[12.0,31.6]$ \\
\hline $20-29$ & $11.5 \%$ & $1,548[1448,1648]$ & $11.3[3.0,19.9]$ \\
\hline $30-39$ & $15.2 \%$ & $1,190[1114,1266]$ & $6.2[0.8,11.6]$ \\
\hline $40-49$ & $17.5 \%$ & $770[713,827]$ & $8.8[2.7,14.6]$ \\
\hline $50-59$ & $12.2 \%$ & $653[591,716]$ & $7.7[1.0,14.7]$ \\
\hline $60-69$ & $7.2 \%$ & $756[667,843]$ & $24.1[8.3,39.8]$ \\
\hline$\geq 70$ & $7.5 \%$ & $1,095[991,1196]$ & $38.3[19.0,57.8]$ \\
\hline \multicolumn{4}{|l|}{ Season } \\
\hline Spring & $25.5 \%$ & $1,566[1496,1631]$ & $56.2[43.5,68.7]$ \\
\hline Summer & $25.6 \%$ & $1,288[1229,1351]$ & $21.2[13.5,29.0]$ \\
\hline Fall & $25.2 \%$ & $1,128[1070,1186]$ & $19.3[11.9,26.7]$ \\
\hline Winter & $23.7 \%$ & $1,438[1369,1503]$ & $38.7[27.9,49.7]$ \\
\hline \multicolumn{4}{|l|}{ Duration of Residence in the Township } \\
\hline$<1$ year & $15.0 \%$ & $2,325[2219,2433]$ & $65.7[47.8,83.5]$ \\
\hline $1-2$ years & $17.2 \%$ & $1,745[1657,1830]$ & $46.0[32.2,60.0]$ \\
\hline $2-3$ years & $15.3 \%$ & $1,226[1150,1304]$ & $33.2[20.7,45.7]$ \\
\hline $3-6$ years & $30.8 \%$ & $923[876,971]$ & $21.9[14.6,28.9]$ \\
\hline$\geq 6$ years & $15.5 \%$ & $712[652,769]$ & $13.1[5.4,21.0]$ \\
\hline Unknown & $6.2 \%$ & $1,938[1786,2090]$ & $37.2[16.1,58.0]$ \\
\hline \multicolumn{4}{|l|}{ Household income quintile of the neighborhood } \\
\hline Low & $4.7 \%$ & $1,482[1329,1634]$ & $63.5[32.5,94.8]$ \\
\hline Medium Low & $10.1 \%$ & $1,559[1452,1665]$ & $40.9[23.7,57.7]$ \\
\hline Medium & $24.1 \%$ & $1,256[1194,1319]$ & $33.6[23.6,43.7]$ \\
\hline Medium High & $43.1 \%$ & $1,391[1340,1438]$ & $29.6[22.5,36.6]$ \\
\hline High & $18.0 \%$ & $1,252[1178,1322]$ & $32.1[20.9,43.6]$ \\
\hline \multicolumn{4}{|l|}{ Drinking Water Disinfection } \\
\hline Chlorination & $38.7 \%$ & $1,343[1293,1394]$ & $27.7[20.7,35.1]$ \\
\hline None & $61.3 \%$ & $1,358[1319,1400]$ & $37.6[30.9,44.2]$ \\
\hline \multicolumn{4}{|l|}{ Water System or Subsystem } \\
\hline $\begin{array}{l}\text { Municipal A*: mixed surface }(66-96 \%) \& \\
\text { well }\end{array}$ & $27.2 \%$ & 1,905 [1832, 1977] & $28.8[20.0,37.3]$ \\
\hline $\begin{array}{l}\text { Municipal B*: mixed surface }(66-96 \%) \& \\
\text { well }\end{array}$ & $8.6 \%$ & $1,741[1619,1865]$ & $29.9[14.3,45.8]$ \\
\hline $\begin{array}{l}\text { Municipal } C^{*} \text { : mixed surface }(12-63 \%) \& \\
\text { well }\end{array}$ & $16.2 \%$ & $949[882,1013]$ & $23.4[13.1,33.6]$ \\
\hline $\begin{array}{l}\text { Municipal } D^{*} \text { : well, with added surface } \\
\text { water in emergencies \& summer }\end{array}$ & $8.8 \%$ & $1,252[1150,1355]$ & $43.1[24.1,61.7]$ \\
\hline $\begin{array}{l}\text { Municipal E*: well, with added surface } \\
\text { water in emergencies \& summer }\end{array}$ & $1.5 \%$ & $829[627,1030]$ & $50.7[1.0,100]$ \\
\hline Municipal F: well, large systems & $14.9 \%$ & $1,340[1257,1421]$ & $54.4[38.1,70.6]$ \\
\hline Municipal G: well, small systems & $0.4 \%$ & $412[142,679]$ & $0[0,216]$ \\
\hline Community well & $1.7 \%$ & $949[747,1154]$ & $11.3[0,33.5]$ \\
\hline Private well & $20.7 \%$ & $949[887,1003]$ & $32.9[22.1,43.5]$ \\
\hline
\end{tabular}


Table 2 Proportions of person-time and crude incidence rates of intestinal infectious diseases, 1995 to 2003 inclusive, stratified by categories of each socio-demographic, temporal, and environmental variable. (Continued)

\begin{tabular}{|c|c|c|c|}
\hline \multicolumn{4}{|l|}{ Sewage Disposal } \\
\hline Municipal sewer user & $52.8 \%$ & 1,701 [1653, 1751] & $39.4[32.3,46.9]$ \\
\hline Private sewer user & $47.3 \%$ & $971[930,1008]$ & $27.0[20.7,33.6]$ \\
\hline \multicolumn{4}{|l|}{ Land Use } \\
\hline Agricultural & $8.3 \%$ & $1,059[962,1157]$ & $32.1[15.2,48.7]$ \\
\hline Residential & $91.7 \%$ & 1,380 [1347, 1413] & $33.9[28.8,39.1]$ \\
\hline \multicolumn{4}{|c|}{ a Number of physician visits $=7,017$ in $189,234,765$ person-days of observation. } \\
\hline \multicolumn{4}{|c|}{$\begin{array}{l}\text { * Systems receiving both well water from municipal wells in the Township and surface water from North Shore Mountain reservoirs. Areas A, B, and C receive } \\
\text { mixed water throughout the year; the estimated proportions of surface water listed above are based on } 2009 \text { total, peak and minimum flows at central } \\
\text { monitoring stations. Areas D and E receive surface water only in emergencies (e.g., system maintenance work) and in peak summer months when well water } \\
\text { levels are low. Township personnel indicated that the water distribution network design suggests additional differences between areas that cannot be quantified, } \\
\text { such that area A is believed to receive more surface water than area B, and area D is believed to receive more surface water than area E. The proportions of } \\
\text { surface water in all five mixed systems vary with rainfall, system water use, and system maintenance. }\end{array}$} \\
\hline
\end{tabular}

included as an additional variable. In another set of models, analyses were restricted to those living at properties receiving municipal water from surface water reservoirs in the North Shore Mountains, and precipitation was included as an additional variable. Precipitation was calculated as a continuous variable then categorized into 6 categories for modelling $(0,1$ to $<10,10$ to $<25$, 25 to $<100,100$ to $<250$, and $\geq 250 \mathrm{~mm}$ ). It was calculated in several ways (accumulated millimetres of rain over one- and two-week periods, with no lag and 2-, 5and 10-day lags), each offered in a separate model.

A number of alternative analysis methods, including Cox proportional hazards and Poisson regression models (classical cohort analysis methods), as well as mixed effects logistic regression and logistic regression with generalized estimating equations (to account for repeated measures on subjects), were considered in the initial stages of data analysis. Due to computational intensity, most of the alternative models were fit on a $10 \%$ (1\% for the mixed effects model) subsample of the original data. The resulting risk estimates and inferential results remained relatively unchanged, with the exception of some categories in the Poisson regression (likely due to rare events and small person-day counts for these categories in the data subsamples). Of particular note is that random intercept logistic regression, which allows for over-dispersed and correlated outcomes arising from repeated measures and clustered design, was fit on a $1 \%$ subsample of the data using PROC GLIMMIX. The estimated variance of the random effects was near 0 , which indicates that the mixed effects logistic regression degenerated to regular logistic regression with no random effects. We were unable to run the mixed effects model on the whole data or on a $10 \%$ subsample, due to insufficient memory. The GEE logistic regression, which accounts for within-subject correlation in repeated measurement designs, was fit using PROC GENMOD for the whole physician visit dataset, assuming exchangeable within-subject correlation. The estimated effects (the point and interval estimates of the beta coefficients) were nearly identical to those under a comparable unconditional logistic regression model fit using PROC LOGISTIC;
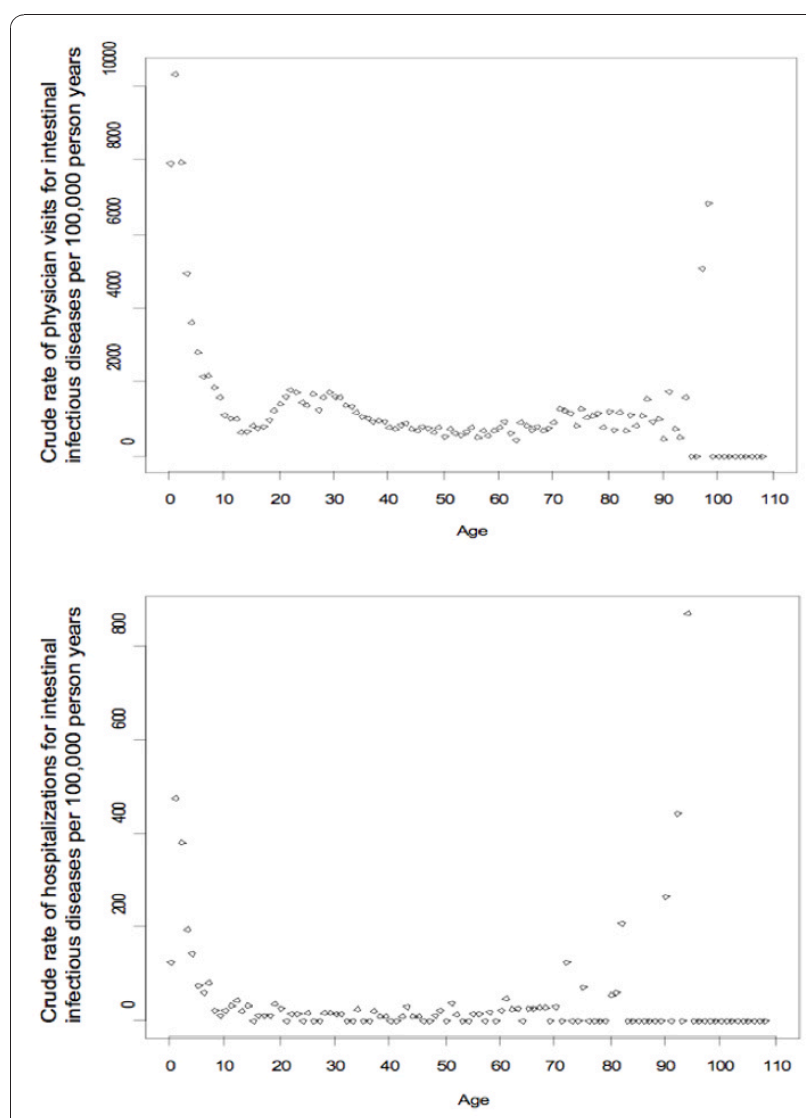

Figure 2 Crude intestinal infectious disease incidence rates vs. age. Data from 1995 to 2003 inclusive: a) $N=7,017$ physician visits in 189,234,765 person-days of observation (top). b) $N=180$ hospitalizations in 194,552,383 person-days (bottom). 
the estimated exchangeable working correlation was close to 0 .

Note that in this cohort analysis, the follow-up on each individual ended at first observation of a disease event or over the available follow-up years for no event ever observed; this may be the reason for observing small and negligible within-subject correlation in the mixed effects and GEE analyses. The computing time for GEE using PROC GENMOD on the whole physician visit data was about 15 days, while the computing time using PROC LOGISTIC was about 2 days. Therefore, the final models were developed using PROC LOGISTIC, which was computationally most efficient among all methods considered.

\section{Results}

The average population of the Township during the study period was 90,273 . The study cohort included 126,499 individuals who resided in the Township for at least 6 months between 1995 and 2003. The analysis dataset for physician visits included 7,017 cases with an intestinal infectious disease and 189,234,765 person-days. The analysis dataset for hospitalizations included 180 cases and 194,552,383 person-days. Person-days differed because the number of days removed after subjects' first events differed. Almost all events had general diagnostic codes not specific to a single organism (Table 1). Plots of disease events by day and week over the study period showed no temporal patterns indicative of outbreaks.

The Township database included 29,458 unique parcels of land (Figure 1). Of the parcels, $30.9 \%$ were recorded as private water users only, $66.3 \%$ were recorded as municipal water users only, though $69.1 \%$ were connected to the municipal water supply at some point during the study period. At the beginning of the study period, no parcels received chlorinated water while over two-thirds $(20,387)$ did by the end of the study, including municipal and community water supplies with surface and well water sources. About half the parcels (49.4\%) had private septic systems only, $48.9 \%$ were connected to the municipal sewer system only, and $50.6 \%$ were connected to the municipal sewer system sometime during the study period. There was a slight decrease in the number of parcels with an agricultural use code from the beginning of the study $(8.1 \%)$ to the end $(7.0 \%)$.

Table 2 lists the proportion of person-time for each category of each variable. These differ from the proportions of parcels outlined above, because the numbers of people living at each parcel were not equally distributed by category.

Crude incidence rates of intestinal infectious diseases were 1,353 physician visits per 100,000 person-years (95\% CI: 1,322-1,385/100,000) and 33.8 hospitalizations per 100,000 person-years (95\% CI: 28.8-38.7/100,000). Table 2 lists the crude incidence rates for each category of each variable. These rates exclude potentially independent subsequent disease episodes after an initial episode. Among 7,017 subjects with a physician visit for an intestinal infectious disease, $23 \%(1,592 / 7,017)$ had multiple billing records for such diseases. Most $(1,410 /$ 1,592) had the same ICD-9 codes for the initial and repeat visits, and more than half (835) had consecutive records less than 3 months apart making it very likely the records were for the same episode. Only $6.5 \%$ of subjects with a physician visit $(454 / 7,017)$ had consecutive billing records more than one year apart. Among 180 subjects hospitalized for an intestinal infectious disease, 3.3\% (6/180) had multiple hospital discharge records for such diseases, all with the same ICD-9 codes for the initial and repeat visits. Five of the 6 subjects with repeat records had second records less than a month after the initial hospitalization, and one had a second hospitalization more than a year later.

Variability in crude incidence rates was greatest for age (Table 2 Figure 2). The pattern of higher rates at the extremes of age was similar for physician visits and hospitalizations The rates were consistently high among those under 5, whereas those in the oldest ages had more variable rates due to small numbers, especially among those over 90 years old for physician visits and over 70 years for hospitalizations (Figure 2). Physician visit rates were also higher among young adults (ages $\sim 20-35)$, but this pattern was not observed for hospitalizations.

Patterns of incidence rates were similar for both physician visits and hospitalizations for many of the other independent variables (Table 2). Seasonal rates were highest in the spring and lowest in the fall. Those who had resided in the Township for fewer years had higher rates. Those living in neighborhoods with the two lowest household income quintiles had higher rates. Rates were lower with chlorinated water, with private sewage disposal systems, and agricultural land uses. There was no clear pattern related to water system, except that those with wells connected to a small number of properties and run either by a private community or by the municipality had the lowest rates.

Table 3 summarizes the results of logistic regressions examining associations between intestinal infectious diseases and the independent variables representing sociodemographic, temporal, and environmental factors. All variables, except land use, were significant in the analysis of physician visits, and supported the patterns observed for the crude incidence rates. The only variables with significant relationships to hospitalizations were age and season. Though not statistically significant, the patterns of the odds ratio estimates for most variables (except socioeconomic status, water system, and 
Table 3 Odds ratios ${ }^{\mathrm{a}}$ and $\mathbf{9 5 \%}$ confidence intervals for associations between physician visits or hospitalizations for intestinal infectious diseases and socio-demographic, temporal, and environmental variables.

\begin{tabular}{|c|c|c|c|c|c|c|}
\hline \multirow[b]{3}{*}{ Variable \& Category } & \multicolumn{3}{|c|}{ Physician Visits } & \multicolumn{3}{|c|}{ Hospitalizations } \\
\hline & \multirow[b]{2}{*}{$\begin{array}{l}\text { Odds } \\
\text { Ratio }\end{array}$} & \multicolumn{2}{|c|}{$\begin{array}{l}\text { Wald } 95 \% \\
\text { Confidence } \\
\text { Limits }\end{array}$} & \multirow[b]{2}{*}{$\begin{array}{l}\text { Odds } \\
\text { Ratio }\end{array}$} & \multicolumn{2}{|c|}{$\begin{array}{l}\text { Wald } 95 \% \\
\text { Confidence } \\
\text { Limits }\end{array}$} \\
\hline & & Lower & Upper & & Lower & Upper \\
\hline \multicolumn{7}{|l|}{ Sex } \\
\hline Female & 1.08 & 1.03 & 1.13 & 1.18 & 0.88 & 1.58 \\
\hline Male & 1.00 & - & - & 1.00 & - & - \\
\hline \multicolumn{7}{|l|}{ Age } \\
\hline$<1$ & 5.22 & 4.26 & 6.40 & 2.75 & 0.60 & 12.6 \\
\hline $1-4$ & 4.83 & 4.32 & 5.39 & 6.54 & 3.64 & 11.8 \\
\hline $5-9$ & 1.81 & 1.61 & 2.04 & 1.33 & 0.69 & 2.58 \\
\hline $10-19$ & 0.80 & 0.71 & 0.90 & 0.54 & 0.27 & 1.07 \\
\hline $20-29$ & 1.31 & 1.17 & 1.47 & 0.26 & 0.11 & 0.64 \\
\hline $30-39$ & 0.96 & 0.86 & 1.08 & 0.14 & 0.05 & 0.40 \\
\hline $40-49$ & 0.69 & 0.61 & 0.78 & 0.22 & 0.09 & 0.51 \\
\hline $50-59$ & 0.63 & 0.55 & 0.72 & 0.20 & 0.07 & 0.56 \\
\hline $60-69$ & 0.69 & 0.59 & 0.80 & 0.62 & 0.27 & 1.42 \\
\hline$\geq 70$ & 1.00 & - & - & 1.00 & - & - \\
\hline \multicolumn{7}{|l|}{ Season } \\
\hline Spring & 1.08 & 1.01 & 1.15 & 1.45 & 1.01 & 2.07 \\
\hline Summer & 0.89 & 0.83 & 0.95 & 0.55 & 0.35 & 0.87 \\
\hline Fall & 0.77 & 0.72 & 0.83 & 0.50 & 0.31 & 0.81 \\
\hline Winter & 1.00 & - & - & 1.00 & - & - \\
\hline \multicolumn{7}{|l|}{ Duration of Residence in the Township } \\
\hline$<1$ year & 1.16 & 1.03 & 1.30 & 1.04 & 0.46 & 2.35 \\
\hline $1-2$ years & 0.98 & 0.88 & 1.09 & 0.89 & 0.40 & 1.95 \\
\hline $2-3$ years & 0.80 & 0.70 & 0.91 & 0.73 & 0.30 & 1.78 \\
\hline $3-6$ years & 0.73 & 0.64 & 0.82 & 0.62 & 0.26 & 1.49 \\
\hline$\geq 6$ years & 0.69 & 0.60 & 0.80 & 0.55 & 0.20 & 1.57 \\
\hline Unknown & 1.00 & - & - & 1.00 & - & - \\
\hline \multicolumn{7}{|l|}{ Household income quintile of the neighborhood } \\
\hline Low & 1.18 & 1.03 & 1.34 & 1.17 & 0.58 & 2.37 \\
\hline Medium Low & 1.19 & 1.07 & 1.32 & 0.91 & 0.49 & 1.69 \\
\hline Medium & 1.06 & 0.98 & 1.15 & 0.85 & 0.51 & 1.42 \\
\hline Medium High & 1.02 & 0.95 & 1.09 & 0.89 & 0.57 & 1.39 \\
\hline High & 1.00 & - & - & 1.00 & - & - \\
\hline \multicolumn{7}{|l|}{ Drinking Water Disinfection } \\
\hline Chlorination & 0.92 & 0.85 & 1.00 & 0.89 & 0.53 & 1.48 \\
\hline None & 1.00 & - & - & 1.00 & - & - \\
\hline \multicolumn{7}{|l|}{ Water System or Subsystem } \\
\hline Municipal A: mixed surface (66-96\%) \& well & 1.57 & 1.39 & 1.78 & 0.54 & 0.24 & 1.20 \\
\hline Municipal B: mixed surface $(66-96 \%) \&$ well & 1.45 & 1.28 & 1.64 & 0.66 & 0.29 & 1.52 \\
\hline Municipal C: mixed surface (12-63\%) \& well & 1.01 & 0.90 & 1.12 & 0.71 & 0.36 & 1.40 \\
\hline Municipal D: well, with surface water added in emergencies \& summer & 1.00 & 0.87 & 1.15 & 0.83 & 0.37 & 1.87 \\
\hline Municipal E: well, with surface water added in emergencies \& summer & 0.89 & 0.69 & 1.15 & 1.35 & 0.45 & 4.03 \\
\hline Municipal F: well, large systems & 0.96 & 0.85 & 1.08 & 0.93 & 0.45 & 1.94 \\
\hline Municipal G: well, small systems & 0.51 & 0.27 & 0.99 & 0 & 0 & $>999$ \\
\hline Community well & 1.04 & 0.83 & 1.30 & 0.34 & 0.05 & 2.49 \\
\hline Private well & 1.00 & - & - & 1.00 & - & - \\
\hline
\end{tabular}


Table 3 Odds ratios ${ }^{a}$ and $95 \%$ confidence intervals for associations between physician visits or hospitalizations for intestinal infectious diseases and socio-demographic, temporal, and environmental variables. (Continued)

\begin{tabular}{|c|c|c|c|c|c|c|}
\hline Municipal sewer & 1.26 & 1.14 & 1.38 & 1.42 & 0.77 & 2.62 \\
\hline Private sewage system & 1.00 & - & - & 1.00 & - & - \\
\hline \multicolumn{7}{|l|}{ Land Use } \\
\hline Agricultural & 1.06 & 0.95 & 1.19 & 0.95 & 0.51 & 1.80 \\
\hline Residential & 1.00 & - & - & 1.00 & - & - \\
\hline
\end{tabular}

${ }^{a}$ Based on unconditional logistic regression, also adjusted for calendar year. Statistically significant odds ratios in bold.

- Reference value, no confidence limits calculated.

land use) were the same for hospitalizations and physician visits.

Well depth was known for 3,815 wells. The mean depth was $36.6 \mathrm{~m}$, with a recorded range of 0 to $280 \mathrm{~m}$. No relationship between well depth and physician visits for intestinal infectious diseases was observed in crude incidence rates or in logistic regression modelling restricted to those living at properties whose well depth was known. Crude incidence rates (and proportion of total person-time) in three well depth categories were: 1,049 /

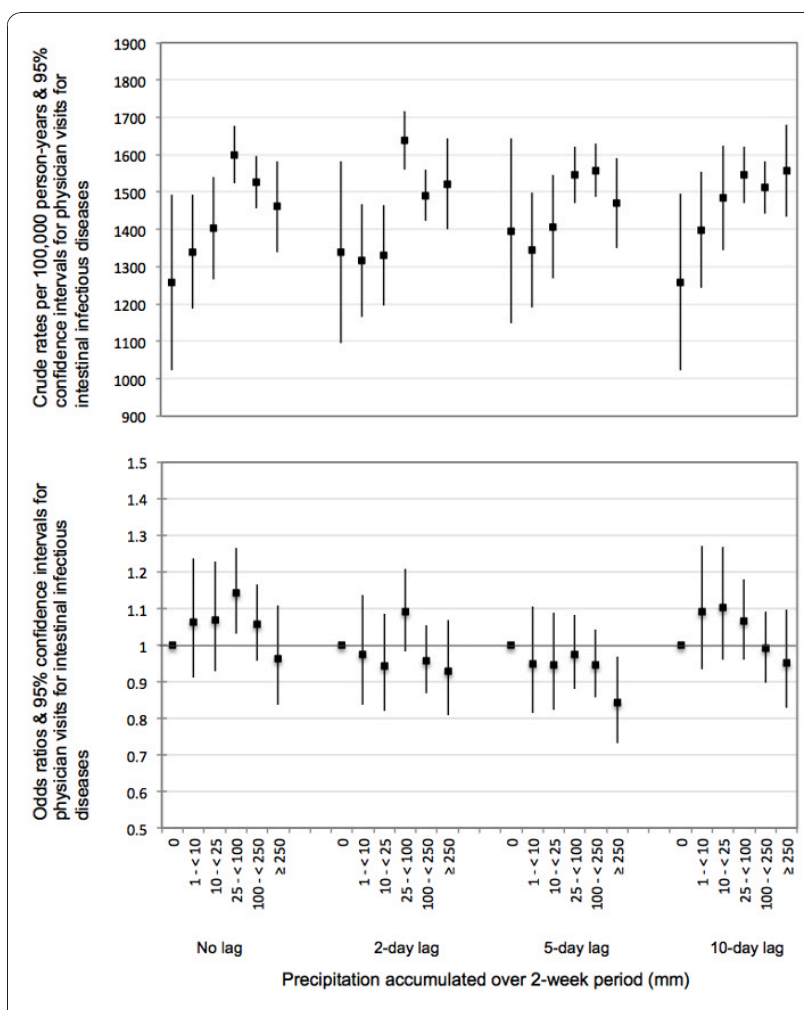

Figure 3 Physician visits for intestinal infectious diseases vs. precipitation accumulated over prior 2 weeks. Data from 1995 to 2003 inclusive; restricted to subpopulation ( $N=4,868$ physician visits and 117,543,309 person-days of observation) that received unfiltered surface water from North Shore Mountain reservoirs. a) Crude incidence rates per 100,000 person-years (top). b) Odds ratios adjusted for sex, age, calendar year, season, duration of residence in the Township, neighborhood household income quintile, drinking water disinfection, water system, sewage disposal, and land use (bottom)
100,000 person-years (2.0\% of person-time) for well depths up to $9 \mathrm{~m} ; 1,089$ (6.2\%) for depths of greater than 9 to $30 \mathrm{~m}$; and 1,032 (8.2\%) for depths greater than $30 \mathrm{~m}$.

The association between precipitation and physician visits for an intestinal infectious disease was examined for those residents receiving municipal water from the North Shore mountain surface water reservoirs $(62.1 \%$ of person-time). No relationship was observed for one-week rainfall accumulations. For two-week accumulations, crude rates suggested a pattern of increasing illness with increasing rainfall, particularly with a 10-day lag (Figure $3 a)$. However, in logistic regressions adjusting for all other variables, the trends did not hold (Figure $3 \mathrm{~b}$ ).

The response rate for the survey of Township households was $59 \%$ ( $N=546$ respondents of 926 eligible; $N=$ 74 were ineligible, including businesses, vacant addresses, mail returned to sender, etc.). Of those responding, $62 \%$ received municipal water, 5\% community water, and 33\% private well water. Almost all households used tap water for cooking (92\%, 95\% CI: 90-94\%), most also used it for drinking (79\%, CI: 76-82\%), and a large proportion filtered their tap water (45\%, CI: 41-49\%). These proportions did not vary by water source. Most respondents with private wells tested their water for coliform bacteria (71\%, CI: 67$75 \%)$ and for nitrates (68\%, CI: 64-72\%). Almost all (88\%, CI: 85-91\%) knew their well depth, with reported depths ranging from 3 to $152 \mathrm{~m}$ and a mean of $39 \mathrm{~m}$, very similar to the mean for wells in the Ministry of Environment database. About 35\% (CI: 31-39\%) of respondents with private wells reported problems with their water. Most were related to minerals and sediment (reported for $17 \%$ of all wells) or the well running dry (5\%), but $12 \%$ reported bacteriological contamination at some point. Contaminated wells were treated, about half with bleach and the other half by installing ultraviolet light disinfection systems. Of those with private sewage systems (49\%; CI: 45-53\%), 97\% reported that the system was a septic tank and drain field. The few other types included engineered systems with biofilters or small treatment plants.

\section{Discussion}

\section{Disease rates}

The crude incidence rates of intestinal infectious diseases found in this study (1,353 physician visits and 33.8 
hospitalizations per 100,000 person-years) are difficult to compare to those reported elsewhere, because of different case definitions and identification methods. The most similar data are for enteric disease hospitalizations in the US from 1998 to 2006; Christensen et al. [20] found a rate of $56.6 / 100,000$, somewhat higher than in this study, likely because they included more ICD-9 codes (001-009, 022.2). Tinker et al. [13] reported emergency department visits for gastrointestinal illnesses in Atlanta and found a rate of about 800/100,000. In a summary of several of his Canadian and US studies, Payment [21] estimated a self-reported gastrointestinal illness (nausea, vomiting, diarrhea) rate of 70,000/ 100,000 . In a modeling exercise to estimate the rate of acute gastrointestinal illness specifically due to drinking water in the US, Messner et al. [22] estimated a rate of $6,000 / 100,000$.

\section{Environmental factors}

The main focus of this study was whether environmental variables related to water quality were associated with intestinal infectious diseases. Chlorination was associated with lower physician visit and hospitalization rates (latter not statistically significant). Even the small reduction in risk suggested by these data may have public health importance, since this is one of the dominant methods of water treatment. Although chlorination has been shown to be effective in preventing enteric disease outbreaks [23], the few reports investigating endemic disease have been less clear. Hellard et al. [11] examined a children's hospital emergency visits (numerator data only) before and after chlorination of the Melbourne, Australia water supply, but found no change. Odoi et al. [15] found no difference in giardiasis rates between areas in Ontario, Canada with and without chlorination.

This study was able to examine numerous types of water systems, and to examine sub-classifications of those systems. We expected that those with private well water would have higher enteric disease rates than those with municipal and community well water, as found by others [16,24-26], though not all [17]. Beyond the effect of chlorination, this was not the case. Two small municipal well water supplies each serving fewer than 100 homes had physician visit rates that were about half those of the private wells, but other municipal and community well water sources had rates similar to private wells. Well depth was not associated with differences in endemic disease rates, lending support to lack of influence of private well water on disease rates, though it is important to note that the subset of wells with known depth was likely to have been correctly constructed to prevent contamination, since well depths were voluntarily reported by professional well drillers. Evidence from the survey suggests that most Township residents with private wells were well informed about their water systems and conscientious about testing them and correcting problems.

We also expected that those served by municipal surface water supplies would have higher disease rates than those served exclusively by municipal well water systems, as found elsewhere $[15,17,24,26,27]$. There was some evidence of this in the physician visit but not the hospitalization data. Of the 5 systems that had mixed surface and well water, the two with the highest proportions of surface water had the highest physician visit rates, about $50 \%$ higher than those served by most other systems types, including those with smaller proportions of surface water. We further investigated the systems receiving surface water, to examine the impact of recent precipitation. While crude rates suggested increased physician visits with increased precipitation, this trend was not robust to adjustment for other variables. A number of investigators have examined both precipitation and the turbidity it can induce. Curriero et al. [28] found that more than half of surface water-related outbreaks were preceded by extreme precipitation in the month prior. Aramini et al. [10] studied Vancouver, which receives all its drinking water from the same protected North Shore mountain watersheds that partially serve areas of the Township. They found associations between increased turbidity and endemic gastroenteritis, as measured by physician visits and hospitalizations. Others have observed similar relationships $[8,14,29]$. In all studies, the associations were small, but significant. These studies did not include the range of variables available about the Township and its residents, so it is unknown whether controlling for other factors would have diminished the associations, as occurred in our analyses.

Although the relationship between sewage contamination and enteric disease outbreaks is well established [30], we identified only two other studies that examined endemic disease risk by sewage system type. Denno et al. [16] found higher odds ratios for Salmonella infection for those with private septic systems. Febriani et al. [17] found no difference in gastrointestinal illness prevalence between those with private and municipal sewage disposal. We expected private septic systems might have drain-field-to-well contamination that could result in higher disease rates. Instead higher disease rates were observed among those with municipal sewer connections for both physician visits and hospitalizations (the latter not statistically significant). This result was apparent in the initial crude analyses and remained after adjustment for all other factors in the models, including the neighborhood-level adjustment allowed by the water system variable. To check whether municipal sewer might be a surrogate for other factors not considered a priori, we 
conducted post hoc analyses including population density and distance to nearest hospital. Neither variable was associated with disease events and the higher odds ratios for municipal sewer remained stable. We also examined disease rates for the interaction of sewage and water system types. There was no difference in rates between private and municipal sewage systems for those with private well water, but those with both municipal sewer and municipal water systems, whose pipes are likely to run along similar paths, had higher disease rates. Although the higher disease rates for municipal sewer users may be a chance finding or may be related to other factors not accounted for in this study, it is prudent to consider possible explanations. The Township does not have combined storm and sanitary sewer lines, so overflow is not an issue. Water lines are required to be separated from sewer lines by $0.5 \mathrm{~m}$ vertically (sewer lines below) and 3 $\mathrm{m}$ horizontally, and where these conditions cannot be met, the water main is to be protected from infiltration by wrapping the pipe joints with petrolatum tape. Although there is no comparable data from the Township, some studies have shown possible modes of contamination despite the care taken when pipes are laid. A US study described sources of sewer line leakage and concluded exfiltration can occur where the groundwater table is below the sewer lines (as is the case in the Township) [31]. Others have found that soil and water samples next to water lines frequently have fecal contamination [32], and that breaks and maintenance work on water lines [12,23] and low water pressure [33] are related to gastrointestinal illness.

\section{Sociodemographic and temporal factors}

Sociodemographic and temporal factors were also associated with infectious intestinal disease rates in this study. Females had higher rates than males in our study, as found elsewhere [20]. The age distributions of physician visits and hospitalizations largely followed a u-shaped pattern of high rates in the very young and elderly, and for physician visits only, of increased rates in young adults as well (an association often thought to be related to travel or parenting young children). Christensen et al. [20] reported the age distribution of hospitalizations for all infections (not just enteric), and the $\mathrm{u}$-shaped pattern was similar to that observed here. The demographic differences in disease rates are likely, in part, to reflect differences in health care utilization across these characteristics.

Hospitalizations and physician visits for enteric diseases were highest from December through May and lowest from June through November, the same pattern observed in a Quebec study of gastrointestinal illness prevalence [17]. In a study of physician billings for enteric diseases in the neighboring Canadian province of Alberta, the highest rates were observed from November through March, and the lowest in September [34]. Christensen et al. [20] examined seasonality for all infectious diseases in the US and found the highest incidence from December through March inclusive and the lowest incidence from June to September. Slight offsets in seasonality may in part reflect differences in climates between the jurisdictions studied.

Lower household income (as an ecological variable, for each census dissemination area) was related to increased physician visits for infectious intestinal diseases, not surprising since income has been similarly associated with many health indicators in Canada, including life expectancy [35]. Studies specific to enteric disease have also found increased rates for those with lower income [15]. A study by Tam et al. [36] raises the question of the extent to which these results reflect differences in disease rates or differences in likelihood of attending a physician by socio-economic status.

Finally, duration of residence was consistently related to disease rates. Those who lived in the Township longer had lower rates of both physician visits and hospitalizations (the latter not statistically significant). Febriani et al. [17] identified a similar pattern. Frost et al. [37] showed that episodes of gastrointestinal illnesses were 35 to $60 \%$ lower among subjects with antigens to Cryptosporidium parvum, suggesting that an explanation of this finding may be increasing immunity to local pathogens over time. It may also be possible that individuals are likely to seek medical advice for enteric illnesses when they first move to an area, but may be less likely to do once they are established in the community.

\section{Strengths and limitations}

This study had the following advantages: a large cohort with almost a decade of follow-up; a cohort design which allowed calculation of disease incidence rates; objective data on dependent and independent variables of interest; and survey data about water-related behaviors in the study area.

There were also limitations. The administrative data on disease events were provided by physicians, not laboratories, therefore clinical suspicion was used to assign general rather than specific disease coding, preventing analyses of individual diseases such as giardiasis or cryptosporidiosis. Because it is difficult to specify a betweenevent period to define second incident events within an individual, we included only first events. The incidence rates for physician visits and hospitalizations are therefore underestimates, though the distribution of subsequent events suggests that this is a small problem, representing an underestimate of $10 \%$ or less. Intestinal infectious diseases do not always result in contacts with the health care system, so the incidence rates calculated here omit less severe events and events among people less inclined to 
visit a physician [36]. If the propensity to visit a physician is related to the main environmental variables of interest, the effect estimates could be biased. We did post-hoc analyses to adjust for factors thought to be related to the propensity for physician visits and hospitalizations (distance to the nearest hospital, population density) and these did not change the results for the environmental variables. In fact, the physician visit results for all independent variables, except land use and precipitation, were stable from the crude rates to the adjusted analyses.

Many of the independent variables, including environmental variables, household income quintile, and duration of residence in the Township, were dependent on the temporal and spatial accuracy of residential address records held by the Client Registry of the Ministry of Health Services. Since address records are updated when the health care system is used, the timeliness of address changes may be related to overall health status. We tested the reliability of selected administrative data via comparisons to data collected in the survey. Despite the 3-year offset between these two data sources and potential errors in the survey data, kappas for agreement beyond chance were 0.76 for water system type and 0.78 for sewage system type, indicating very good reliability. Finally, details on certain features were not available, for example well and septic system ages, and water quality at the tap of individual residences.

\section{Conclusions}

The study is one of few that have examined risk of physician visits and hospitalizations for endemic infectious intestinal diseases across an array of water and sewer system types. Chlorination of water supplies was shown to be associated with lower risks. Surface water was associated with higher risks in two of five systems. Private well water was not associated with increased risk, likely because of awareness of water quality and quantity issues by Township residents. Those with municipal sewer systems appeared to have increased disease risk, though this result needs to be viewed with caution since it was not anticipated and has not been observed elsewhere. Further studies to examine disease incidence among populations with municipal versus private sewage systems are warranted. Most socio-demographic variables had predicted associations, with higher physician visit and hospitalization rates in females, in the very young and very old, and in those in low income areas. Increased duration of residence in the Township was associated with reduced risk, perhaps due to increasing immunity to local pathogens over time.

For public health and civil engineering personnel, these results reinforce confidence in chlorination as a means of reducing enteric disease risk, and indicate that private well water users who understand their systems and know how to respond to water quality issues identified during monitoring can minimize disease risks. The results also convey cautions: they support previous research indicating that surface water sources, even with protected watersheds, deserve special attention; and present new data suggesting municipal sewer systems may require more scrutiny than previously thought.

The results of this study, which did not always follow prior expectations, underscore the importance of studying factors associated with endemic disease across water and sewage system types.

\section{List of Abbreviations}

BC: Canadian province of British Columbia; Cl: confidence interval; ICD-9: International Classification of Diseases, $9^{\text {th }}$ edition; OR: odds ratio.

\section{Acknowledgements}

We greatly appreciate the work of Antigone Dixon-Warren, Meaghan Norton Daniel, Dean Scovill and the many other personnel of the Township of Langley and Fraser Health Authority who helped with introducing the project to the region, assembling the data sets, and interpreting the results. We thank Negar Elmieh, AJ Gunson, Jennifer Hinton, Elizabeth Matovinovic, Karen McCaig, John Rowse, Carolina da Silva, and Sylvia Struck for their work in the initial stages of this project, John Spinelli and Nhu Le for analytical advice, Suhail Marino and Saleema Dhalla for their work on the opinion survey, and members of the Program on Water Governance for their helpful comments about the results. The study was funded in part by the Canadian Institutes of Health Research, the Canadian Water Network, and the Bridge Program at the University of British Columbia.

\section{Author details}

${ }^{1}$ School of Population and Public Health, University of British Columbia, Vancouver, Canada. ${ }^{2}$ Department of Civil Engineering, University of British Columbia, Vancouver, Canada. Institute for Resources, Environment and Sustainability, University of British Columbia, Vancouver, Canada. ${ }^{4}$ Department of Pathology and Laboratory Medicine, University of British Columbia and BC Centre for Disease Control, Vancouver, Canada.

\section{Authors' contributions}

$K T$ led the design, conduct, and analysis of the study and drafted the paper. NB led the environmental data gathering, conducted the ArcGIS linkage, liaised with the Ministry of Health Services for the linkage of the environmental data to the cohort data, and participated in interpretation of results and manuscript review. $H$ Shen conducted the data analyses and participated in interpretation of results and various stages of the manuscript reviews and revisions. JA had the initial idea for the study, and participated in the design, analyses, interpretation, and manuscript revisions. RC managed the linked dataset, screened the cohort for eligibility, and used Ministry billings data to define cases. MK led the application to Population Data BC, participated in data analyses, interpretation, and manuscript review. YCM participated in the study design, analyses, interpretation and in various stages of the manuscript reviews and revisions. H Schreier, and JLI-R participated in the study design, analyses, interpretation and manuscript review. All authors have read and approved the final manuscript.

\section{Competing interests}

The authors declare that they have no competing interests.

Received: 24 February 2010 Accepted: 16 December 2010 Published: 16 December 2010

\section{References}

1. Yoder J, Roberts V, Craun GF, Hill V, Hicks LA, Alexander NT, Radke V, Calderon RL, Hlavsa MC, Beach MJ, Roy SL: Surveillance for waterborne disease and outbreaks associated with drinking water and water not intended for drinking - United States, 2005-2006. MMWR Surveill Summ 2008, 57:39-62. 
2. MacKenzie WR, Hoxie NJ, Proctor ME, Gradus MS, Blair KA, Peterson DE, Kazmierczak JJ, Addiss DG, Fox KR, Rose JB, Davis JP: A massive outbreak in Milwaukee of Cryptosporidium infection transmitted through the public water supply. New England J Med 1994, 331:161-167.

3. Krewski D, Balbus J, Butler-Jones D, Haas C, Isaac-Renton J, Roberts KJ, Sinclair M: Managing health risks from drinking water - a report to the Walkerton inquiry. J Toxicol Environ Health A 2002, 65:1635-823.

4. O'Connor D: Report of the Walkerton Commission of Inquiry, Parts 1 and 2. Ontario Ministry of the Attorney General; 2002 [http://www. attorneygeneral.jus.gov.on.ca/english/about/pubs/walkerton/], (Accessed Feb. 8, 2010).

5. Livernois J: The Economic Costs of the Walkerton Water Crisis The Walkerton Inquiry Commissioned Paper 14. The Walkerton Inquiry: Toronto; 2001 [http://www.uoguelph.ca/ live/Livernois_14\%20Final\%20Report.pdf], (Accessed Feb. 8, 2010).

6. BC Centre for Disease Control: 2008 British Columbia Annual Summary of Reportable Diseases BC CDC: Vancouver; 2009 [http://www.bccdc.ca/NR/ rdonlyres/59BFCFBB-933D-4337-9305-E3E5FF30D272/0/ EPI_Report_CDAnnual2008_20091202.pdf], (Accessed Feb. 8, 2010).

7. Public Health Agency of Canada: Notifiable Disease Incidence by Year, 1989 to 2004. 2009 [http://dsol-smed.phac-aspc.gc.ca/dsol-smed/ndis/ c_time-eng.php], (Accessed Feb. 8, 2010).

8. Schwartz J, Levin R, Hodge K: Drinking water turbidity and pediatric hospital use for gastrointestinal illness in Philadelphia. Epidemiol 1997 8:615-620.

9. Morris RD, Naumova EN, Griffiths JK: Did Milwaukee experience waterborne cryptosporidiosis before the large documented outbreak in 1993? Epidemiol 1998, 9:264-270.

10. Aramini J, McLean M, Wilson J, Holt J, Copes R, Allen B, Sears W: Drinking water quality and health-care utilization for gastrointestinal illness in greater Vancouver. Can Commun Dis Rep 2000, 26:211-4.

11. Hellard ME, Sinclair MI, Dharmage SC, Bailey MJ, Fairley CK: The rate of gastroenteritis in a large city before and after chlorination. Int J Environ Health Res 2002, 12:355-360.

12. Nygard K, Wahl E, Krogh T, Tveit OA, Bohleng E, Tverdal A, Aavitsland P: Breaks and maintenance work in the water distribution systems and gastrointestinal illness: a cohort study. Int J Epidemiol 2007, 36:873-880.

13. Tinker SC, Moe CL, Klein M, Flanders WD, Uber J, Amirtharajah A, Singer $P$, Tolbert PE: Drinking water residence time in distribution networks and emergency department visits for gastrointestinal illness in Metro Atlanta, Georgia. J Water Health 2009, 7:332-43.

14. Tinker SC, Moe CL, Klein M, Flanders WD, Uber J, Amirtharajah A, Singer P, Tolbert PE: Drinking water turbidity and emergency department visits for gastrointestinal illness in Atlanta, 1993-2004. J Expo Sci Environ Epidemiol 2010, 20:19-28.

15. Odoi A, Martin SW, Michel P, Holt J, Middleton D, Wilson J: Determinants of the geographical distribution of endemic giardiasis in Ontario, Canada: a spatial modeling approach. Epidemiol Infect 2004, 132:967-76.

16. Denno DM, Keene WE, Hutter CM, Koepsell JK, Patnode M, Flodin-Hursh D, Stewart LK, Duchin JS, Rasmussen L, Jnes R, Tarr PI: Tri-county comprehensive assessment of risk factors for sporadic reportable bacterial enteric infection in children. J Infect Dis 2009, 199:467-76.

17. Febriani $Y$, Levallois P, Gingras S, Gosselin P, Majowicz SE, Fleury MD: The association between farming activities, precipitation, and the risk of acute gastrointestinal illness in rural municipalities of Quebec, Canada: a cross-sectional study. BMC Public Health 2010, 10:48.

18. Chamberlayne R, Green B, Barer ML, Hertzman C, Lawrence WJ, Sheps SB: Creating a population-based linked health database: $A$ new resource for health services research. Can J Public Health 1998, 89:270-273.

19. World Health Organization: International Classification of Diseases, 9 th Revision World Health Organization: Geneva, Switzerland;1979-1998.

20. Christensen KLY, Holman RC, Steiner CA, Sejvar JJ, Stoll BJ, Schonberger LB: Infectious disease hospitalizations in the United States. Clin Infect Dis 2009, 49:1025-1035.

21. Payment P: Epidemiology of endemic gastrointestinal and respiratory diseases: incidence, fraction attributable to tap water and costs to society. Water Sci Tech 1997, 35:7-10.

22. Messner M, Shaw S, Regli S, Rotert K, Blank V, Soller J: An approach to developing a national estimate of waterborne disease due to drinking water and a national estimate model application. J Water Health 2006, 4(Suppl2):201-240
23. Tulchinsky TH, Burla E, Clayman M, Sadik C, Brown A, Goldberger S: Safety of community drinking-water and outbreaks of waterborne enteric disease: Israel, 1976-97. Bull World Health Org 2000, 78:1466-73.

24. Carrique-Ma J, Andersson Y, hjertqvist M, Svensson A, Torner A, Giesecke J: Risk factors for domestic sporadic campylobacteriosis among young children in Sweden. Scand J Inf Dis 2005, 37:101-10.

25. Roy SL, DeLong SM, Stenzel SA, Shiferaw B, Roberts JM, Khalakdina A, Marcus R, Segler SD, Shah DD, Thomas S, Vugia DJ, Zansky SM, Dietz V, Beach MJ: Emerging Infections Program FoodNet Working Group. Risk factors for sporadic Cryptosporidiosis among immunocompetent persons in the United States from 1999 to 2001. J Clin Microbiol 2004, 42:2944-51.

26. Dennis DT, Smith RP, Welch JJ, Chute CG, Anderson B, Herndon JL, von Reyn CF: Endemic Giardiasis in New Hampshire: A case-control study of environmental risks. J Inf Dis 1993, 167:1391-5.

27. Adak GK, Cowden JM, Nicholas S, Evans HS: The Public Health Laboratory Service national case-control study of primary indigenous sporadic cases of campylobacter infection. Epidemiol Infect 1995, 115:15-22.

28. Curriero FC, Patz JA, Rose JB, Lele S: The association between extreme precipitation and waterborne disease outbreaks in the United States, 1948-1994. Am J Public Health 2001, 91:1194-9.

29. Schwartz J, Levin R, Goldstein R: Drinking water turbidity and gastrointestinal illness in the elderly of Philadelphia. J Epidemiol Community Health 2000, 54:45-51.

30. Schuster CJ, Ellis AG, Robertson WJ, Charron DF, Aramini JJ, Marshall BJ, Medeiros DT: Infectious disease outbreaks related to drinking water in Canada, 1974-2001. Can J Public Health 2005, 96:254-8.

31. Selvakumar A, Field R, Burgess EH, Amick RS: Exfiltration in sanitary sewer systems in the US. Urban Water Journal 2004, 1:227-234.

32. Karim MR, Abbaszadegan M, LeChevallier M: Potential for pathogen intrusion during pressure gradients. J Am Water Works Assoc 2003, 95:134-46.

33. Hunter PR, Chalmers RM, Hughes S, Syed Q: Self-reported diarrhea in a control group: A strong association with reporting of low-pressure events in tap water. Clin Infect Dis 2005, 40:32-4.

34. Yiannakoulias N, Svenson LW: Differences between notifiable and administrative health information in the spatial-temporal surveillance of enteric infections. Int J Med Inform 2009, 78:417-424.

35. Mclntosh CN, Fines P, Wilkins R, Wolfson MC: Income disparities in healthadjusted life expectancy for Canadian adults, 1991 to 2001. Health Reports 2009, 20:1-10.

36. Tam CC, Rodrigues LC, O'Brien SJ: The study of infectious intestinal disease in England: what risk factors for presentation to general practice tell us about potential for selection bias in case-control studies of reported cases of diarrhoea. Int J Epidemiol 2003, 32:99-105.

37. Frost FJ, Roberts M, Kunde TR, Craun G, Tollestrup K, Harter L, Muller T: How clean must our drinking water be: The importance of protective immunity. J Infect Dis 2005, 191:809-14.

\section{Pre-publication history}

The pre-publication history for this paper can be accessed here: http://www.biomedcentral.com/1471-2458/10/767/prepub

\section{doi:10.1186/1471-2458-10-767}

Cite this article as: Teschke et al: Water and sewage systems, sociodemographics, and duration of residence associated with endemic intestinal infectious diseases: A cohort study. BMC Public Health 2010 10:767. 